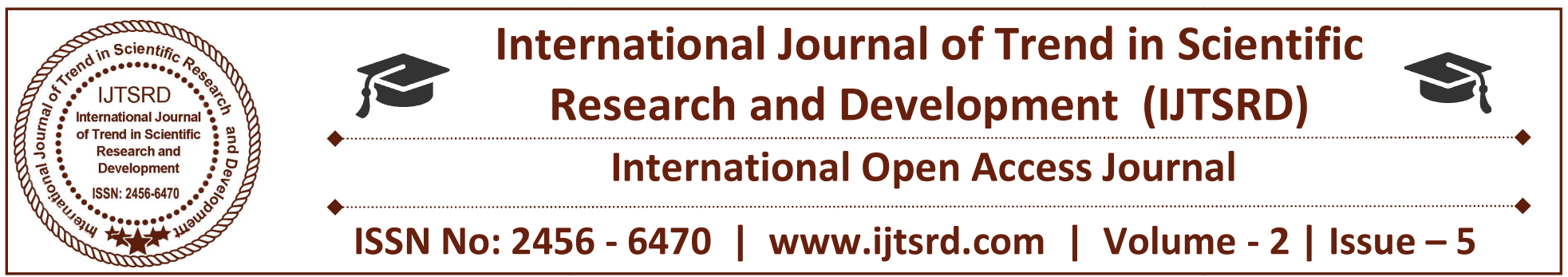

\title{
Azadirachta Indica A. Juss. Leaf Extract Mediated Synthesis of Silver Nanoparticles and their Antibacterial Efficacy Against Selected Human Pathogens
}

\author{
T. Leon Stephan Raj, J. Vijayakumari， M. Menaga \\ Department of Botany, St. Xavier's College (Autonomous), Palayamkottai, \\ Affiliated to Manonmaniam Sundaranar University, Abhisekapatti. \\ Tirunelveli, Tamil Nadu, India
}

\section{ABSTRACT}

The present study deals with the biological synthesis of silver nanoparticles (AgNPs) from the leaves of Azadirachta indicia and their efficacy against human pathogens. Azadirachta indicia has the potent medicinal properties and used in different aspects of traditional medicines. The presence of silver nanoparticles was confirmed by the formation of brown color of the reaction mixture. The green synthesized silver nanoparticles were characterized by Fourier transmission infrared spectroscopy (FT-IR) analysis and X-ray diffraction (XRD). FT-IR revealed that the functional groups were observed and capped with plant secondary metabolites. X-ray diffraction was used to confirm the crystalline nature of the particles. Antibacterial activity of silver nanoparticles was performed by agar disc diffusion method against Staphylococcus aureus, E. coli, Klebsiella pneumoniae, Enterococcus faecalis and Pseudomonas aeruginosa. The highest zone of inhiitionof silver nanoparticles synthesized by Azadirachta indica extracts was found against Klebsiella pneumoniae (17 $\mathrm{mm}$ ). The silver nanoparticle synthesized in this process has the efficient antibacterial activity against pathogenic bacteria. It can be used in the field of medicine, due to their high antibacterial activity.

Keywords: Azadirachta indica, FT-IR, Antibacterial activity, Green synthesis and Silver anaoparticles

\section{INTRODUCTION}

Nan biotechnology is the recently emerging field in biological research. Green synthesis of silver nanoparticles using plant extract was eco-friendly approach in nanotechnology. It is a new form of nanotechnology which has produced a great development of different fields. The nanomaterials play an ever increasing role in science, research and development as well as also in every day's life, and more products based on nonmaterial was introduced to the market. Various approaches available for the synthesis of silver nanoparticles include physical, chemical, electrochemical, radiation, photochemical method, and biological techniques [1]. Biological synthesis process provides a wide range of environment friendly, low cost production and minimum time required. At the same time the biologically synthesized silver nanoparticles has many applications includes catalysts in chemical reactions. Different types of nonmaterial like zinc, copper [2], gold [3], alginate [4] and silver have come up but silver nanoparticles have proved to be most effective as it has good antimicrobial efficacy against bacteria, viruses and other eukaryotic microorganisms [5].

It has been proved by various biological materials such as bacteria both gram positive and gram negative like Bacillus subtilis and Klebsiella planticola [6, 7], Cladosporium cladosporioides [8], marine algae Turbinaria conoides and Padina tetrastromatica [9, 10], the peels of banana fruits [11], carbohydrate molecules like polysaccharide and disaccharides starch, sucrose, maltose, and monosaccharide's like glucose and fructose $[12,13]$. There have been several reports on the synthesis of silver nanoparticles using medicinal plants such as Cinnamomum camphora [14], Nelumbo nucifera [15], Garcinia mangostana 
[16], pomegranate [17] and grape fruit extracts [18]. Recently, some studies have shown that specially formulated Ag NPs have good antibacterial activity [19]. Azadirachta indica is an important medicinal plant of the family Meliaceae. In this paper, we report on the synthesis of silver nanoparticles by the reduction of aqueous $\mathrm{Ag}+$ ion by simultaneous reduction of aqueous $\mathrm{Ag}+$ with the leaf extract of medicinal plant. The morphological, crystalline and biochemical characters of green synthesized silver nanoparticles were analyzed by X-ray diffraction assay and Fourier transform infrared spectroscopy. Finally the medical property of the silver nanoparticle was characterized using antibacterial assay against Staphylococcus aureus, E. coli, Klebseilla pneumonia, Enterococcus faecal is and Pseudomonas aeruginosa.

\section{II.Materials and methods}

\section{A. Selection and collection of plant material}

The experimental material selected for the present study is Azadirachta indica (Neem) belongs to the family Meliaceae. The plant material was collected from the region of Tirunelveli and based on the cost effectiveness, easy of availability and medicinal property identified with the help of herbarium specimens deposited in St. Xavier's College Herbarium $(\mathrm{XCH})$. Fresh and healthy leaves were collected and thoroughly first rinse with tap water followed by distilled water to remove all the dust and unwanted visible particles.

\section{B. Extract for Na no Particle Isolation}

$10 \mathrm{~g}$ of fresh leaf was boiled with $100 \mathrm{ml}$ of double distilled water. The extraction was filtered through what man no. 1 filter paper. The filtered samples were collected in a conical flask. The obtained extract was used for the synthesis of silver nanoparticles.

\section{Preparation of Silver Nitrate Solution}

$1 \mathrm{mM}$ silver nitrate solution was prepared by the concentration of $0.0169 \mathrm{~g}$ in $100 \mathrm{ml}$ double-distilled water and stored.

\section{Metal-Plant Extracts Interaction}

$90 \mathrm{ml}$ of silver nitrate solution was taken in a conical flask. To this $10 \mathrm{ml}$ of the extract was added. The colour change of the silver nitrate solution was found from colourless to dark brown.

\section{E. Concentration of Phyto Nanoparticles}

After 72 hrs of incubation, the colour change was observed. This indicated that the silver nanoparticles were synthesized from the plant materials with the help of aqueous solution. Then this solution was taken in a centrifuge at $10,000 \mathrm{rpm}$ for 20 mins. The pellets were taken after centrifugation and mixed with petroleum ether for rapid drying, dried pellets were collected in a micro-centrifuge tube and the pellets were used for testing antibacterial activity.

\section{F. FTIR analysis}

To remove any free biomass residue or compound that is not the capping ligand of the nanoparticles, the residual solution of $100 \mathrm{ml}$ after reaction was centrifuged at $5000 \mathrm{rpm}$ for $10 \mathrm{~min}$ and the resulting suspension was redispersed in $10 \mathrm{ml}$ sterile distilled water. The centrifuging and redispersing process was repeated three times. Thereafter, the purified suspension was freeze dried to obtain dried powder. Finally, the dried nanoparticles were analyzed by FTIR Nicolet Avatar 660 (Nicolet, USA).

\section{G. XRD Analysis}

The characterization of purified synthesized silver nanoparticles were freeze dried powered and used for XRD analysis (XRD, model name) at $40 \mathrm{kv} / 20 \mathrm{~mA}$ using continuous scanning 2 delta mode [20]. The silver nanoparticles solution was purified by repeated centrifuged at 5000rpm for 20minute followed by redispersion of the pellet of silver nanoparticles into $10 \mathrm{ml}$ of deionised water.

\section{H. Antibacterial Activity of SNPs}

The antibacterial activity of isolated plant SNP pellets were tested by agar disc diffusion method. The test organisms used for the assay are Staphylococcus aureus, E. coli, Klebsiella pneumoniae, Enterococcus faecalis and Pseudomonas aeruginosa. The antibacterial activity of the synthesized silver nanoparticle was evaluated by measuring the zone of inhibition method. The samples for each bacterial strain were sub-cultured in individual agar slants.

\section{Preparation of Sterile Antibiotic Discs}

Antibacterial activity assay against selected human pathogens were done by agar disc diffusion method. What man no.1 filter paper of $5 \mathrm{~mm}$ diameter was used; these discs were sterilized before use for the preparation of discs. The extracts of the SNP solution were added to the sterile disc was incorporated individually with 200-500 $\mu 1$ extract of SNP solution using a micropipette. Precautions were taken to prevent the flow of the solvent extract from the outer surface of the discs. The condensed extracts were 
applied in small quantities and the discs were allowed for air-drying. Then another dose of the extract was applied.

\section{J. Assay of Antibacterial Activity}

Muller-Hinton agar broth was prepared in ten test tubes. The tubes were cotton plugged, autoclaved and labelled according to the type of the bacterial cultures to be inoculated. The Muller-Hinton agar broth was incubated at $37 \pm 1.5{ }^{\circ} \mathrm{C}$ for 18 hours. After the incubation period, the inhibition zones around the discs were measured and recorded. Three replicates for each concentration were carried out.

\section{Result and discussion}

A. Synthesis and characterization of Silver Nanoparticles

Silver nanoparticles formation in Azadirachta indica leaf extract after treated with silver nitrate aqueous solution showed a colour change from yellow to brown within $2 \mathrm{~min}$. The colour change was clear indication for the formation of silver nanoparticles [21]. When silver salt (AgNO3) is added to aqueous leaf extract of Azadirachta indica it results into a color change from pale yellow to yellowish - brown and finally to dark - brown color. The reduction of silver ions to metallic silver is due to the presence of reducing agents. It was suggested that compounds like caffeine and the ophyl line act as reducing agent when Acalypha indica leaf extract was used [22].

\section{B. FT-IR Analysis}

FTIR spectrum of Azadirachta indica leaf mediated synthesized silver nanoparticles was displayed in figure 1. The results indicated the presence of bio molecules involved in the reduction process. The smaller peak found at $1245.24 \mathrm{~cm}^{-1}$ represents the C$\mathrm{O}, \mathrm{C}-\mathrm{N}, \mathrm{P}-\mathrm{H}, \mathrm{P}=\mathrm{O}$ stretches are Carboxylic acids, Ester, Amines, Phosphine, Phosphonate and Phosphor amide, $1283.58 \mathrm{~cm}^{-1}$ peak may be due to the aromatic group of Amine Oxide (N-O); the peak at $1459.30 \mathrm{~cm}^{-}$ ${ }^{1}$ is due to the $=\mathrm{C}$ stretch of aromatic; the peak at $1636.07 \mathrm{~cm}^{-1}$ shows $\mathrm{NH} 2, \mathrm{C}=\mathrm{O}, \mathrm{C}=\mathrm{C}$ stretch's of Amines, Amides, Alke ne and $2106.61 \mathrm{~cm}^{-1}$ corresponding to $\mathrm{C}-\mathrm{C},-\mathrm{N}=\mathrm{C}=\mathrm{O},-\mathrm{N}=\mathrm{C}=\mathrm{S}-\mathrm{N}=\mathrm{C}=\mathrm{N}-$, N3, C $=\mathrm{C}=\mathrm{O}$, Si-H stretch's of Alkyne, Isocyanates, Isothiocyanates, Diimides, Azides, Ketenes and Silane; $2364.29 \mathrm{~cm}^{-1}$ indicates P-H stretch of phosphine, the major peak at $3306.05 \mathrm{~cm}^{-1}$ is due to the C-H, O-H stretch's of Alky ne and Alcohol (Table. 1). FT-IR revealed that carboxyl and amine groups may be involved in the reduction and stabilizing mechanism. The observed peaks are mainly attributed to flavonoids and terpenoids excessively present in plant extract [23]. The peak observed at $1283.54 \mathrm{~cm}^{-1}$ indicate the presence of alkyk halide, The band at $1072.35 \mathrm{~cm}^{-1}$ is due to ether linkages and suggest the presence of flavanones adsorbed on the surface of metal nanoparticles [24]. Another one report also suggested that the involvement of water-soluble flavonoid in the reduction of metal ions using plant extracts [25].

\section{Figure: 1. FT-IR spectrum of silver nanoparticles Synthesized by Azadirachta indica.}

Table: 1. FT-IR spectral values and functional groups of Azadirachta indica.

\begin{tabular}{|c|c|c|c|}
\hline S. No & Peak Values $\left(\mathrm{cm}^{-1}\right)$ & Functional Group & Class \\
\hline 1. & 1245.24 & $\mathrm{C}-\mathrm{O}, \mathrm{C}-\mathrm{O}, \mathrm{C}-\mathrm{N}, \mathrm{P}-\mathrm{H}, \mathrm{P}=\mathrm{O}, \mathrm{P}=\mathrm{O}$ & $\begin{array}{c}\text { Carboxylic Acids, Ester, Amines, Phosphine, } \\
\text { Phosphonate, Phosphoramide }\end{array}$ \\
\hline 2. & 1283.58 & Aromatic & Amine Oxide (N-O) \\
\hline 3. & 1459.30 & $\mathrm{C}=\mathrm{C}$ & Amines, Amides, Alkene \\
\hline 4. & 1636.07 & $\mathrm{NH}, \mathrm{C}=\mathrm{O}, \mathrm{C}=\mathrm{C}$ & $\begin{array}{c}\text { Alky ne, Isocyanates, Isothiocyanates, } \\
\text { Diimides, Azides, Ketenes, Silane }\end{array}$ \\
\hline 5. & 2106.61 & $\begin{array}{c}\mathrm{C}-\mathrm{C},-\mathrm{N}=\mathrm{C}=\mathrm{O},-\mathrm{N}=\mathrm{C}=\mathrm{S}- \\
\mathrm{N}=\mathrm{C}=\mathrm{N}-,-\mathrm{N} 3, \mathrm{C}=\mathrm{C}=\mathrm{O}, \mathrm{Si}-\mathrm{H}\end{array}$ & Phosphine \\
\hline 6. & 2364.29 & $\mathrm{P}-\mathrm{H}$ & Alky ne, Alcohol \\
\hline 7. & 3306.05 & $\mathrm{C}-\mathrm{H}, \mathrm{O}-\mathrm{H}$ & Unknown \\
\hline 8. & 3736.90 & Unknown & Unknown \\
\hline 9. & 3790.89 & Unknown & Unknown \\
\hline 10. & 3822.39 & Unknown & Unknown \\
\hline 11. & 3854.34 & &
\end{tabular}




\section{XRD measurement}

Structural and crystalline nature of the silver nanoparticles has been performed using XRD analysis. Figure 1 showed that the biosynthesized silver nanostructure by using Azadirachta indica leaf extract. It was demonstrated and confirmed by the seven characteristic peaks observed in the XRD image at $2 \theta$ values ranging from 30 to 90 . The seven intense peaks were 27.3324, 32.2991, 38.1870, 44.6924, $46.2466,64.5030$ and 77.4682 corresponding to the height of $122.28,88.27,208.95,58.90,53.47,53.25$ and 80.14 for silver nanoparticles of neem. The corresponding' spacing value of $\mathrm{Ag}$ nanoparticles were $3.26302,2.77170,2.35681,2.02770,1.96312$, 1.44469 and 1.23211 for synthesised leaf nanoparticles. The result indicated that the silver nanoparticle synthesized by leaf extract is crystalline in nature. The XRD pattern thus clearly showed that the silver nanoparticles are crystalline in nature. Similar report was obtained using cell filtrate of Streptomyces $s p$. ERI-3 synthesized extracellularly [26]. The biosynthesized silver nanoparticle by employing Cipadessa baccifera leaf extracts were further demonstrated and confirmed by the characteristic peaks observed in XRD analysis [27].

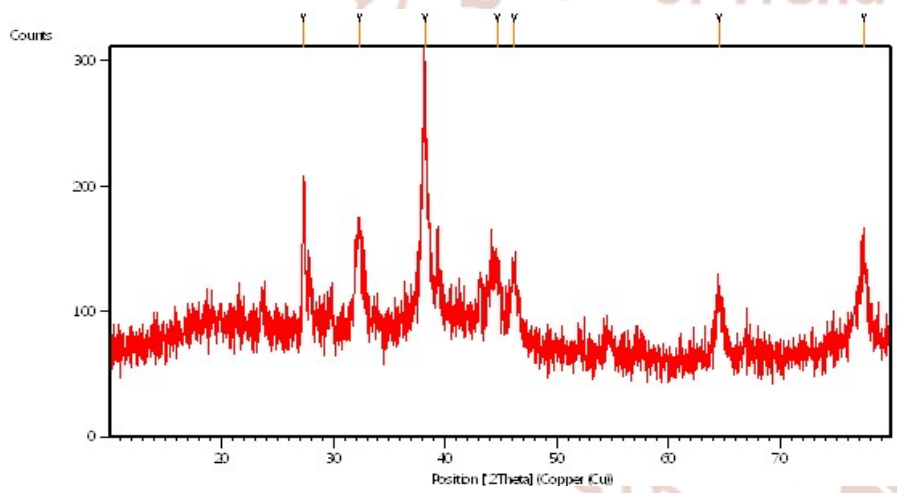

Figure 2. XRD Spectrum of Silver nanoparticles of Azadirachta indica.

\section{Antibacterial Activity}

Antibacterial activity of synthesized silver nanoparticles was performed against Staphylococcus aureus, E. coli, Klebsiella pneumoniae, Enterococcus faecalis and Pseudomonas aeruginosa by disc diffusion method. The antibacterial activity of synthesized silver nanoparticles was compared with plant extract and commercial antibiotic disc. The zone of inhibition was measured and denoted in millimetre in diameter. Among the five antibacterial agents, silver nanoparticles highly inhibit the growth of pathogenic bacteria. Highest inhibition was noted against Staphylococcus aureus, E. coli, Klebsiella pneumoniae, Enterococcus faecalis and Pseudomonas aeruginosa.

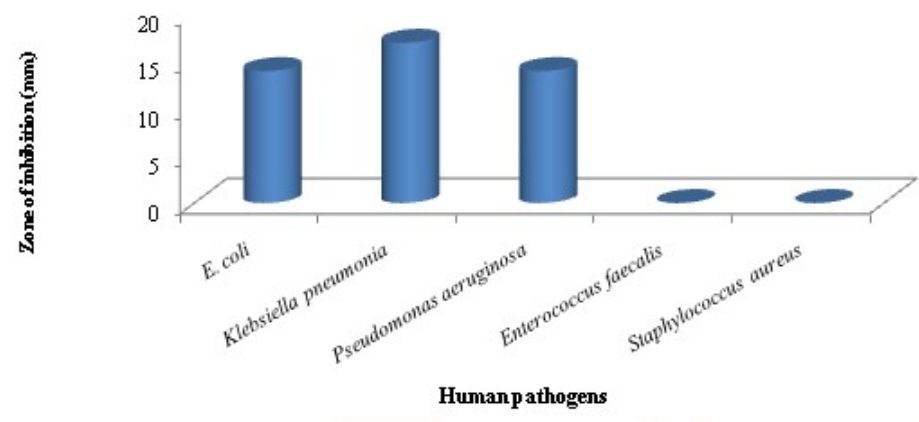

Figure: 3. Antibacterial activity of the SNPs of Azadirachta indica leaf extract

In the present study, Azadirachta indica leaf extract showed significant zone of inhibition against some human pathogenic bacteria. The maximum zone of inhibition was observed in Klebsiella pneumoniae (17 $\mathrm{mm}$ ) against leaf extract synthesized silver nanoparticles. The other pathogens like Pseudomonas aeruginosa and $E$. coli were showed $(14 \mathrm{~mm})$ of zone of inhibition. Staphylococcus aureus showed less zone of inhibition compared to other pathogens. The absence or very low zone of inhibition was observed against Staphylococcus aureus and Enterococcus faecalis. (Figure 3). Silver nanoparticles, due to their antimicrobial properties have been used most widely in the health industry, medicine, textile coatings, food storage, dye reduction, wound dressing, antiseptic creams and a number of environmental applications [28].

\section{Conclusion}

In conclusion, the biological synthesis of silver nanoparticles was successfully obtained from bio reduction of silver nitrate solutions using neem leaf extracts. The visual observation for the colour changes from pale yellow to brown colour indicated the presence of silver nanoparticles. FT- IR analysis represented the functional group present in the silver nanoparticles. X- RD analysis indicated that the particle nature of the nanoparticles was crystalline like structure. The current study reported that the biologically synthesized silver nanoparticle could be used in the medical field against human diseases due to their high efficiency as antibacterial agent and also different fields of science like biomedical, pharmacology, other scientific research. 


\section{Reference}

1. D.P. Mukhopahayay, A. Satapathy, and P. Banerjee, "Leaf extract mediated green synthesis of silver nanoparticles from widely available Indian plants: synthsis, characterization, antimicrobial property and toxicity analysis," Bioresource and Bioprocessing. 1, 3. 2014.

2. P.S. Schabes, G. Canizal, R. Becerra-Herrera, C. Zorrila, H.B. Liu, and A.A. Ascencio, "Biosynthesis and characterization of $\mathrm{Ti} / \mathrm{Ni}$ bimetallic nanoparticles ," Opt. Mater. 29, 95-99. 2006.

3. H. Gu, P.L. Ho, E. Tong, L. Wang, and B. Xu B, "Presenting vancomycin on nanoparticles to enhance antimicrobial activities," Nano Lett. 3, 1261-1263. 2003.

4. Z. Ahmad, R. Pandey, S. Sharm, and G.K. Khuller, "Alginate nanoparticles as ant tuberculosis and drug carriers: formulation development, pharmacokinetics and therapeutic potential. Ind. J. Chest Dis. Allied Sci, 48, 171176. 2005.

5. P. Gong, H. Li, X. He, K. Wang, and B. Xu, "Preparation and antimicrobial activity of $\mathrm{Fe}_{3} \mathrm{O}_{4}$ (a) Ag nanoparticles," Nanotechnology. 18, 604611. 2007.

6. A.R. Shahverdi, S. Minaeian, H.R. Shahverdi, H. Jamalifar, and A.A. Nohi, "Rapid synthesis of silver nanoparticles using culture supernatants of Enter bacteria: a novel biological approach", Process Biochemistry. vol. 42, no. 5, pp. 919923. 2007.

7. K. Paulkumar, S. Rajeshkumar, G. Gnanajobitha, M. Vanaja, C. Malarkodi, and G. Annadurai, "Eco-friendly synthesis of silver chloride nanoparticles using Klebsiella planticola (MTCC 2277)," International Journal of Green Chemistry and Bioprocess. vol. 3, no. 1, pp. 12-16. 2013.

8. D.S. Balaji, S. Basavaraja, R. Deshpande, D.B. Mahesh, B.K. Prabhakar, and A. Venkataraman, "Extracellular biosynthesis of functionalized silver nanoparticles by strains of Cladosporium cladosporioides fungus," Colloids and Surfaces B: Biointerfaces. vol. 68, no. 1, pp. 88-92. 2009.

9. S. Rajeshkumar, C. Kannan, G. Annadurai, "Green synthesis of silver nanoparticles using marine brown Algae Turbinaria conoides and its antibacterial activity," International Journal of
Pharma and Bio Sciences. vol. 3, no. 4, pp. 502510. 2012.

10. S. Rajeshkumar , C. Kannan, G. Annadurai, "Synthesis and characterization of anti microbial

silver nanoparticles using marine brown seaweed Padinate trastromatica," Drug Invention Today. vol. 4, no. 10, pp. 511-513. 2012.

11. A. Bankar, B. Joshi, A.R. Kumar, andS. Zinjarde, "Banana peel extract mediated novel route for the synthesis of silver nanoparticles," Colloids and Surfaces A: Physicochemical and Engineering Aspects. vol. 368, no. 1-3, pp. 58-63. 2010.

12. D. Manno, E. Filippo, M.D. Giulio, and A Serra, "Synthesis and characterization of starchstabilized Ag nano structures for sensors applications. Journal of Non-Crystalline Solids. vol. 354, no. 52- 54, pp. 5515- 5520. 2008.

13. E. Filippo, A. Serra, A. Buccolieri, and D. Manno, "Green synthesis of silver nanoparticles with sucrose and maltose: morphological and structural characterization," Journal of NonCrystalline Solids. vol. 356, no. 6-8, pp. 344-350. 2010.

14. J. Huang, Q. Li, and D. Sun, "Biosynthesis of silver and gold nanoparticles by novel sun dried Cinnamomum camphora leaf," Nanotechnology. vol. 18, no. 10, Article ID 105104. 2007.

15. T. Santhoshkumar, A.A. Rahuman, and G. Rajakumar G, "Synthesis of silver nanoparticles using Nelumbo nucifera leaf extract and its larvicidal activity against malaria and filariasis vectors," Parasitology Research. vol.108, no.3, pp. 693-702. 2011.

16. P. Karthiga, R. Soranam, and G. Annadurai, "Alpha-mangostin, the major compound from Garcinia mangostana Linn. Responsible for synthesis of Ag Nanoparticles: its characterization and Evaluation studies," Research Journal of Nanoscience and Nanotechnology. vol. 2, no. 2, pp. 46-57. 2012.

17. G. Gnanajobitha, S. Rajeshkumar, G. Annadurai, and C. Kannan, "Preparation and characterization of fruit- mediated silver nanoparticles using pomegranate extract and assessment of its antimicrobial activities," Journal of Environmental Nanotechnology. vol. 2, no. 1, pp. 4-10. 2013. 
18. G. Gnanajobitha, K. Paulkumar, and M. Vanaja, "Fruit mediated synthesis of silver nanoparticles using Vitis vinifera and evaluation of their antimicrobial efficacy," Journal of Nanostructure in Chemistry. vol.3, no.67, pp.1-6. 2013.

19. M.B. Ahmad, K. Shameli, M. Darroudi, W.M.Z.W. Yunus, N.A. Ibrahim, A.A. Hamid, and M. Zargar, "Antibacterial activity of silver/clay/chitosan bio nano composites," Res. J. Biol. Sci. 4: 1156-1161. 2009.20.

20. A. Absar, S. Shankar, and S. Murali, "Geranium leaf biosynthesis of silver nanoparticles," Biotechnology prong. 19, pp 1627-31. 2003.

21. J. Subramani, P.C. Josekutty, A.R. Mehta, and P.N. Bhatt, "Solasodine levels in Solanum sisymbriifolium Lam," Indian Journal of Experimental Biology. vol. 27, no. 2, p. 189. 1989.

22. Krishnaraj, E.G. Jagan, S. Rajasekar, P. Selvakumar, P.T. Kalaichelvan, and N. Mohan, "Synthesis of silver nanoparticles using Acalypha indica leaf extracts and its antibacterial activity against water borne pathogens. Colloids and Surfaces B:," Bio interfaces. 76 (1), pp 50-56. 2010 .

23. P. Benerjee, M. Satapathy, Mukhophaya, and P. Das, "Leaf extract mediated green synthesis of silver nanoparticles from widely available Indian plants; synthesis, characterization, antimicrobial activity and antitoxity analysis," Bio resources and Bio processing. 1,1-10. 2014.
24. S.S. Shankar, A. Rai, A. Ahmad, and M. Sastry $\mathrm{M}$, "Rapid synthesis of $\mathrm{Au}, \mathrm{Ag}$, and bimetallic $\mathrm{Au}$ core-Ag shell nanoparticles using Neem (Azadirachta indica) leaf broth," Journal of Colloid and Interface Science. 275 (2), pp496502. 2004.

25. N. Prabhu, D.T. Raj, G.K. Yamuna, S.S. Ayisha, and I.D.J. Puspha, "Synthesis of silver phyto nanoparticles and their anti-bacterial efficacy," Dig J Nanomater Bios. 5, pp185-189. 2010.

26. R. Arunachalam, S. Dhanasingh, B. Kalimuthu, M. Uthirappan, C. Rose, and A.B. Mandal, "Phytosynthesis of silver nanoparticles using Coccinia grandis leaf extract and its application in the photo catalytic degradation. Colloids and Surfaces B:," Bio interfaces. vol. 94, pp. 226-230. 2012.

27. E. Jebarubi, S. Christopher Patrick Kiladi, and T. Leon Stephan Raj, "Eco-Friendly Synthesis of Silver mediated Nanoparticles using the Leaf extracts of Cipadessa baccifera (Roth) Miq," Arabian Journal of Medicinal \& Aromatic Plants. V3 N (2) 101-107. 2017.

28. X. Gao, J.J. Youtrick, V.D. Topping, T. Black, N. Olejnik, and Z. keltner, et al., "Toxic genomic study in a rat thymus of $\mathrm{fl}$ generation off offspring following maternal exposure to silver ion," Toxicology Reports Volume 2, Pages 341350. 2015. 